\title{
Design, Assembly and Quality Testing of Feeder Panel
}

\author{
${ }^{1}$ Palaash Pandit, ${ }^{2}$ Kaushal Patel \\ ${ }^{1}$ B.Tech Student, ${ }^{2}$ Assistant Professor, \\ Department of Electrical Engineering, \\ Indus University, Ahmedabad, Gujrat, India
}

\begin{abstract}
To design the feeder panel according to the load and requirement of the consumer preparing the general arrangement diagram and the wiring diagram. According to the general arrangement assembling of Bus bars, Circuit breaker and MCCB. Also drawing of wire for the control of the panel and for the power to the control circuit. Quality testing for checking for the requirement to be achieved for the consumer.
\end{abstract}

Keywords_Designing, Assembling, Quality testing.

\section{INTRODUCTION}

The feeder panel is used for the distribution of the power for different uses and as per the requirement of consumer. It is also used for the interconnection between the different supply and also synchronism with the diesel generator sets as the backup supply. The feeder panel generally consists of MCCB's for the distributions to the output ranging from 16Amp to 630Amps and the ACB's for the incoming lines and the output ranging from 630Amp to 3200Amp. For controlling of the panel we use the Contactors, push buttons, selector switches as per the requirement. With all the controlling and power components for the manipulation of the supply indication and metering are also installed in the panel like light bulbs for different applications and with the Voltmeters, Ampermeters, MFM, CT's, etc.

The following are the General sections of a feeder panel:-

$>$ Incomer section (TR)

$>$ Bus-coupler section (BC)

$>$ Output section $(\mathrm{O} / \mathrm{P})$

In above general sections of the feeder panel the Bus-coupler section is been the removed or added more as per the application or the number of incoming sections

\section{GENRAL OVER VIEW}

The design of the feeder panel starts from the requriments and Single line diagram sent from the consumer. The work starts from the making list of the components, designing of the shell of the panel (fabrication) and electrical designing, to be used to meet the requirement of the consumer. After the Fabrication is completed as per the design, the assembling of the components is been completed component like MCCB's, Circuit breakers, Meters, Indications for Phases(R, Y, B), Current transformers. The wires are drawn for metering, Control Circuit, Power Circuit. After the completion of the assembling of the panel the Quality testing of the panel is done by the Q.C and the panel is dispatched for the installation at the site.

\section{DESIGNING}

The designing is the first step of the production of the panel for designing there are some components that are necessary for it the following are as below:-

$>$ The requirement sent by the receiver of the panel

$>$ The single line diagram including incoming line outgoing line for the applications

$>\quad$ The make list for the components to be used

$>$ The rateing of the I/P lines and the applications

After receiving the above information we should start the design process as per the requirement sent by the consumer. We the designer decide the placement of the bus bar as per the space available for the panel installation and the quantity of the bus bar as per the cost of the production of the panel. The following are the different placements of the bus bar:-

$>$ Overhead Bus bar single tier Circuit breaker

$>$ Mid Bus bar single tier Circuit breaker

$>$ Overhead Bus bar double tier Circuit breaker

The Mid bus bar single tier circuit breaker arrangement is generally used were the space is less required for the installation of the panel and also were there is an issue of the cost because the quantity of the bus bar is used less

\section{Outer shell of the panel}

- After deciding the placement of the bus bar according to the usage of the space the designer design the outer shell of the panel and the main part of the outer shell is the box fabricated for the installation of the circuit breaker to be placed and installed in the shell the dimension of the box is as per the IEC standard the table show the standard used:-

- Front cable alley (MCCB)

\begin{tabular}{|c|c|}
\hline Ampere rating & $\begin{array}{c}\text { Dimension of the box } \\
\text { (mm*mm) }\end{array}$ \\
\hline $630 \mathrm{Amp}$ & $400 * 400$ \\
\hline $400 \mathrm{Amp}$ & $400 * 400$ \\
\hline $320 \mathrm{Amp}$ & $400 * 400$ \\
\hline $280 \mathrm{Amp}$ & $300 * 300$ \\
\hline $100 \mathrm{Amp}$ & $300 * 300$ \\
\hline $80 \mathrm{Amp}$ & $300 * 250$ \\
\hline $16 \mathrm{Amp}$ & $300 * 250$ \\
\hline
\end{tabular}




\section{- Rear cable alley (MCCB)}

\begin{tabular}{|c|c|}
\hline Ampere rating & $\begin{array}{c}\text { Dimension of the box } \\
(\mathbf{m m} * \mathbf{m m})\end{array}$ \\
\hline $630 \mathrm{Amp}$ & $600 * 400$ \\
\hline $400 \mathrm{Amp}$ & $600 * 400$ \\
\hline $320 \mathrm{Amp}$ & $600 * 400$ \\
\hline $280 \mathrm{Amp}$ & $450 * 300$ \\
\hline $100 \mathrm{Amp}$ & $450 * 300$ \\
\hline $80 \mathrm{Amp}$ & $450 * 250$ \\
\hline $16 \mathrm{Amp}$ & $450 * 250$ \\
\hline
\end{tabular}

- Air break circuit

\begin{tabular}{|c|c|}
\hline Ampere rating & $\begin{array}{c}\text { Dimension of the box } \\
\text { (mm*mm) }\end{array}$ \\
\hline $630 \mathrm{Amp}$ & $700 * 700$ \\
\hline $800 \mathrm{Amp}$ & $700 * 700$ \\
\hline $3200 \mathrm{Amp}$ & $1000 * 700$ \\
\hline $4000 \mathrm{Amp}$ & $1000 * 700$ \\
\hline $5000 \mathrm{Amp}$ & $1200 * 700$ \\
\hline $6300 \mathrm{Amp}$ & $1200 * 700$ \\
\hline
\end{tabular}

The above tables are of the standard used for the design of the outer shell and the width of the panel. The above dimensions are without any metering and with basic indications like on off status indication. The dimensions will change and will be increased with addition of the meters, selector switches and extra indication of status.
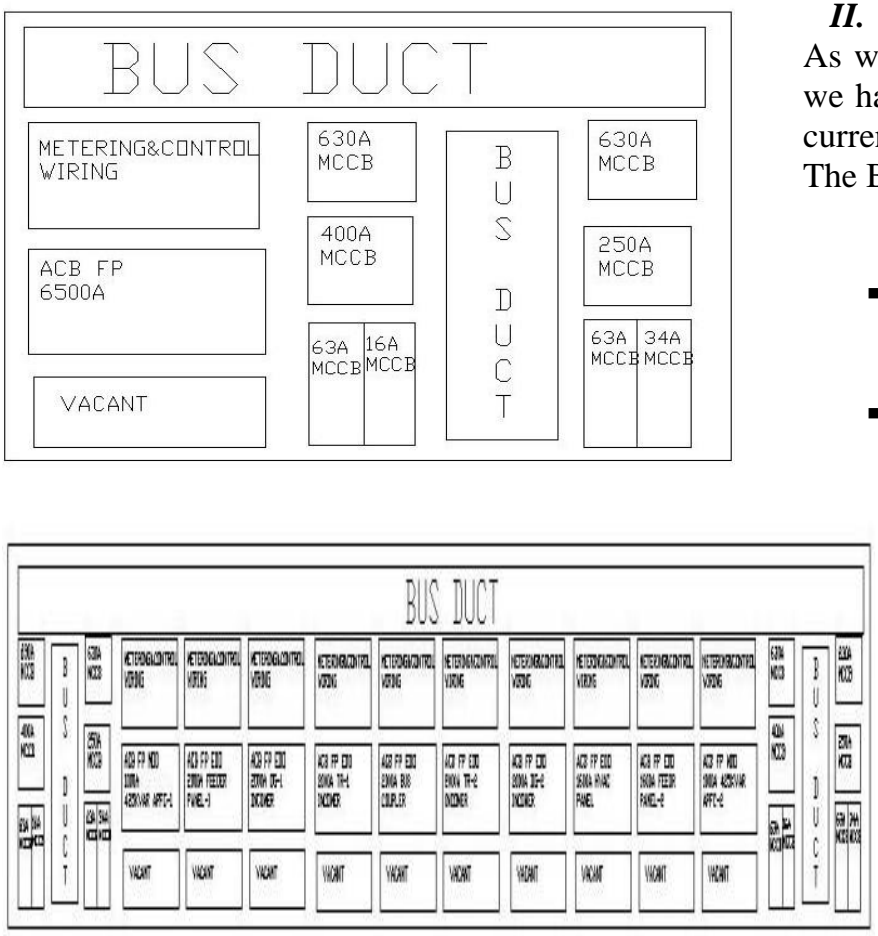

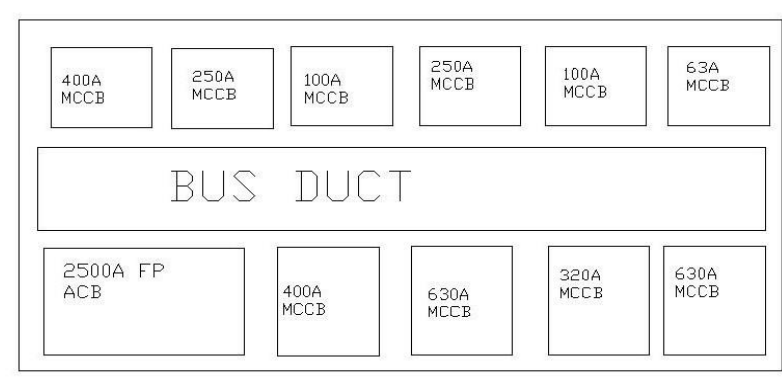

\section{- $\quad \mathrm{MCB}$}

The MCB box is to be selected as the number of the MCB's the following is the common size to be used the height of the box is fixed to the $250 \mathrm{~mm}$ but the width will increase as the quantity. If there are 2 MCB's the width selected is $300 \mathrm{~mm}$ and the width will increase as the quantity like 3 MCB's the width will be increased to $400 \mathrm{~mm}$.

Now if the line of the MCB is increased the height for 2 line will be $400 \mathrm{~mm}$, 3line will be $550 \mathrm{~mm}$ and 4 line will be $700 \mathrm{~mm}$. The line of the MCB should not be more then 4 line it is the general rule for the switch board using MCB's.

\section{Selection of the Bus Bars}

As we have decided the location of the bus bar in the panel we have to select the bus bar as per the requirement and the current capacity of the panel.

The Bus Bars could be of 2 types:-

$$
\begin{aligned}
\text { I. } & \text { Copper } \\
\text { II. } & \text { Aluminum }
\end{aligned}
$$

\section{- Thumb rule}

For Aluminum:-0.8Amp/1Sq mm of bar

For Copper:-1.6Amp/1Sq mm of bar

- Points to be consider while doing sizing calculation

$>$ Adequate minimum required clearance between 2 phases and phase to earth.

$>$ Selection of adequate bus bar insulator standoff.

> Bolting arrangement for continuous bus bar connections.

$>$ Thermal effects on bus bar and insulator standoffs under normal and fault condition.

$>$ Electrodynamic forces applied to bus bar and insulator standoff under fault conditions.

$>$ Avoidance of mechanical resonance under normal operating and fault conditions.

Temperature rise

Maximum permissible temperature rise for bolt connected devices including bus bars. 


\begin{tabular}{|l|c|}
\hline $\begin{array}{c}\text { MATERIAL AND } \\
\text { DIELECTRIC } \\
\text { MEDIUM }\end{array}$ & $\begin{array}{c}\text { MAXIMUM } \\
\text { PERMISSIBLE } \\
\text { TEMPERATURE }\left({ }^{\circ} \mathrm{C}\right)\end{array}$ \\
\cline { 1 - 1 } Bolted connection & \\
\hline $\begin{array}{l}\text { Bare copper, Bare } \\
\text { copper alloy, Bare } \\
\text { aluminum alloy }\end{array}$ & \\
\hline In air & $90^{\circ} \mathrm{C}$ \\
\hline In Sf6 & $115^{\circ} \mathrm{C}$ \\
\hline In oil & $100^{\circ} \mathrm{C}$ \\
\hline
\end{tabular}

- Consider ambient temperature of $40^{\circ} \mathrm{C}$.

- Source reference:-IEC 62271-1

- The general equations that is used for the sizing Co-efficient factors ' $\mathrm{K}$ '

The Total ' $\mathrm{K}$ ' factor derived from six ' $\mathrm{K}$ ' factors, Which is listed below

- $\mathrm{K}=\mathrm{K}_{1} * \mathrm{~K}_{2} * \mathrm{~K}_{3} * \mathrm{~K}_{4} * \mathrm{~K}_{5} * \mathrm{~K}_{6}$

- $\mathrm{K} 1=$ Function of the No. of Bars Per phase and their space

- $\mathrm{K} 2=$ Corresponds to the surface finish of the bus bars

- $\mathrm{K} 3=$ Function of the mounting arrangement

- $\mathrm{K} 4=$ Function of the installed location

- K5=Function of any artificial ventilation

- $\mathrm{K} 6=$ Function of the type of current

Rated current $\mathrm{I}=$ Total ' $\mathrm{K}$ ' factor $*$ Main Formula

- Bus Bar clearances

\begin{tabular}{|c|c|c|}
\hline Voltage (V) & $\begin{array}{c}\text { Phase to Phase } \\
\text { Clearance }(\mathbf{m m})\end{array}$ & $\begin{array}{c}\text { Phase to Earth } \\
\text { Clearance }(\mathbf{m m})\end{array}$ \\
\hline $415 \mathrm{~V}$ & 19 & 16 \\
\hline $600 \mathrm{~V}$ & 25 & 19 \\
\hline $11000 \mathrm{~V}$ & 127 & 77 \\
\hline
\end{tabular}

- Requirement of the consumer

Breaker size needed- 1250Amp ACB

Transformer secondary full load current $=1066.72 \mathrm{Amp}$

\section{- According to thumb rule}

$>$ For copper:-1.6Amp/1Sqmm of Bar For area 800 Sq.mm [80*10mm] the current carrying capacity will be $1280 \mathrm{Amp}$

So, according to formula as per IEC-622711

- $\mathrm{K}=\mathrm{K}_{1} * \mathrm{~K}_{2} * \mathrm{~K}_{3} * \mathrm{~K}_{4} * \mathrm{~K}_{5} * \mathrm{~K}_{6}$

$\mathrm{K}=1 * 1 * 1 * 0.8 * 1 * 1$ $=0.8$

Rated current $\mathrm{I}=$ Total ' $\mathrm{K}$ ' factor $*$ Main Formula

1250Amp $=0.8 *$ Main Formula

Main formula derived value will be = 1562.5Amp

Rated Current $=0.8 * 1562.5$

$=1250 \mathrm{Amp}$

- To carry the current of 1066.72Amp one runner of $80 * 10 \mathrm{~mm}$ of copper is enough.

\section{Wiring of the panel}

The feeder panel consists of 2 type of wiring as follows:-

- Control wiring.

- Power wiring.

The wiring is been design as per the requirement of the consumer. The control wiring includes the indication and metering of the panel, the bus coupler wiring is also important and the auto manual operation selector wiring is a part of the control wiring. The power wiring includes the wiring of the control feeder for the power the wires are generally taken from the bus bar.

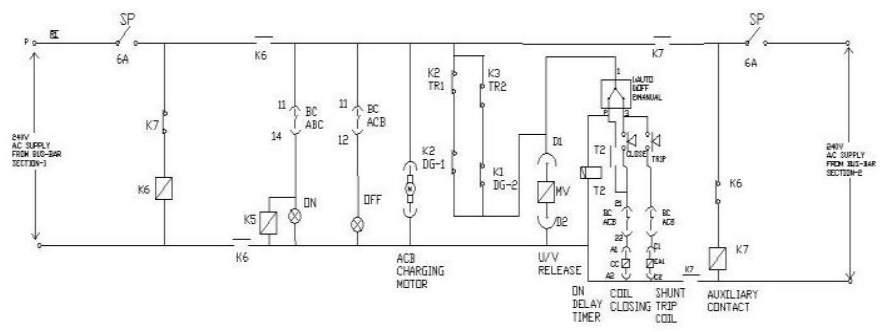

Figure:- Bus coupler wiring diagram

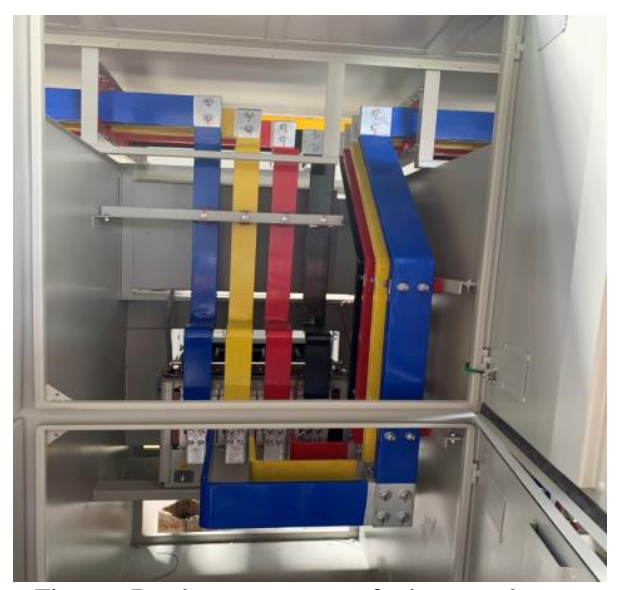

Figure:- Bus bar arrangement for bus coupler

- The above figure shows the wiring diagram of the bus coupler it is used to satisfy the conditions of interlocking.

- The below table shows the interlocking conditions (Auto/Manual) for the above shown bus coupler.

\begin{tabular}{|c|c|c|c|c|}
\hline TR-1 & DG-1 & BC & TR-2 & DG-2 \\
\hline ON & OFF & ON & OFF & OFF \\
\hline OFF & ON & ON & OFF & OFF \\
\hline OFF & OFF & ON & ON & OFF \\
\hline OFF & OFF & ON & OFF & ON \\
\hline ON & OFF & OFF & OFF & ON \\
\hline OFF & ON & OFF & OFF & ON \\
\hline ON & OFF & OFF & OFF & ON \\
\hline OFF & ON & OFF & ON & OFF \\
\hline
\end{tabular}


- The auto manual indicates the breaker would be operated by the push buttons in case of manual operations and in case of auto operation the breaker operates by the supply to the breaker directly and if the selector switch is on the auto and the breaker should not operate by the push buttons.

- This is the last step for the designing after this step the fabricators start the fabrication work as per the approved drawing of the outbox (Shell).

\section{Assembly}

- Installation of the equipment in the shell finished with powder coating and ready to be assembled. The breakers are been installed in 2 parts the cradle case and the contacts box. When the installation of the ACB and MCCB is been completed the bus bar are been sent for the making as per the design. The fabrication of the bus bar is been done in some steps.

- The following steps shows the steps of the bus bar fabrication:-

I. Selecting the size of bus bar as per the specifications of the design.

II. Measuring the length of the bus bar and marking the bends.

III. Making any one bus bar for checking the accessibility in the bus duct and to the ACB or MCCB.

IV. Approving the bus bar by the designer as a sample if not change in bend and change in length if any changes needed from the designed bus bar.

V. Approved from the designer making of the same sets for all 3 phases as per the approved sample.

VI. Fitting the bus bar in the panel with the help of supporters and spacers as the specified area.

VII. Tighten the face plate and connect the bus bar sections with each other connecting the bus couplers with the other 2 sides of the bus coupler.

Checking the tightness of the all the parts of the bus bar connected with the bolt and nut.

\section{- Wiring:-}

The wiring is the most important part of the panel because the controlling of the panel and some low power transmission is also done through wire. The control wiring is usual done with $2.5 \mathrm{Sq} \mathrm{mm}$ copper wire or the $1.5 \mathrm{Sq} \mathrm{mm}$ copper wire. We have to draw the wire as per the designed diagram in the panel and select the wire as specified by the designer. The contactors are used for the interlocking the panel in auto or manual mode. The contacts of the ACB are being also connected as per the wiring diagram. The connection of the CT's is been done to the meter for the metering of the panel.

- There are some extra accessories to the ACB and MCCB from its already included parts some of the parts are mentioned below.

I. Secondary isolating contact and electrical position indicator and cradle secondary isolating contact block.

II. Volt-meteric releases for U-power ACB

III. Closing coil for U-power ACB

IV. Mechanical type door inter lock

V. Operation counter for U-power ACB

- There are also some Supplementary modules used to provide addition protection to basic protection and control circuit are listed below

- ZSI module

- PS module

- AO module

- DIO module

- Relay module

- TCS module

- EL module

- REF module

- The earthing strip is been installed at the bottom of the panel made of copper generally the green wire is been connected between the door and the frame of the panel as earthing.

\section{- Quality Testing}

- The last process of the panel fabrication is to check the panel meets the requirement of the consumer. There are some test listed below for checking the quality of the panel after the process of assembly is been completed.

- Verification of Bill of material as per approved GA drawing

- Overall dimensions as per approved GA drawing

- Tightness of bus bar joints and pull test of crimping of lugs (on random basis)

- Provision of partitions and shrouds \& effectiveness of safety shutters

- Electrical clearances and creepage distance

- Earth continuity / earthing system

- Operational test as per scheme drawing

- Wiring check as per scheme drawing

- Phase sequence / Polarity check

- Overall appearance and surface finish

- Verticality of panels

- Waviness of doors etc.

- Neatness of wiring

- Accessibility \& adequacy of space for external cabling / wiring termination

- Insulation resistance

- High voltage test

- Dry film thickness test

- CT polarity test

- Bus bar joint resistance test 


\section{- Temperature rise test}

- Testing of metering and indication

- The supply is given to the control indication and metering circuit through MCB board the glowing of lamp, volt meter, ampere meter and setting of MFM meters by installing the $\mathrm{CT}$ ratio in the meter. Testing of breaker operation

The supply is given to the breaker and the operation of opening and closing was performed multiple times. The breaker should perform the tripping and connecting operation successfully without any problem. At the time of trip condition the current should be zero and in the connected condition rated current must be noted.

- Testing of interlocking condition

The panel is given supply and by selecting the manual mode the ON-OFF condition of the breaker would be checked as the table. The condition should be satisfy in any mode the breaker in a interlock condition should not be operated like if TR-1 is in off condition and the interlock condition is satisfy then the TR-1 should not be turned on in any mode.

\section{- Contact resistance test}

This test is performed by the contact resistance kit. The kit has an auto transformer and a resistance meter like meggar to get the resistance between the contacts of a bus bar with another contact of the bus bar with the face plate in the connection between 2 contact. The resistance should not be more then 0.2 micro-ohm.

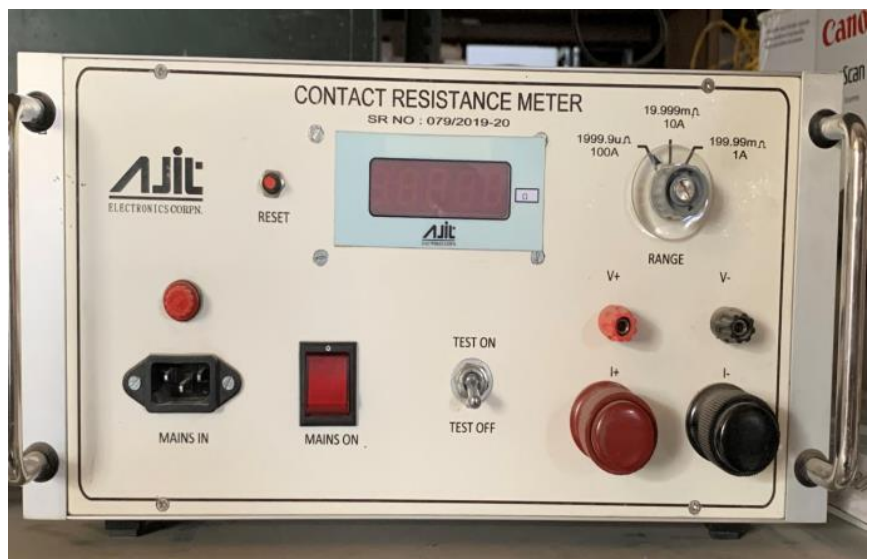

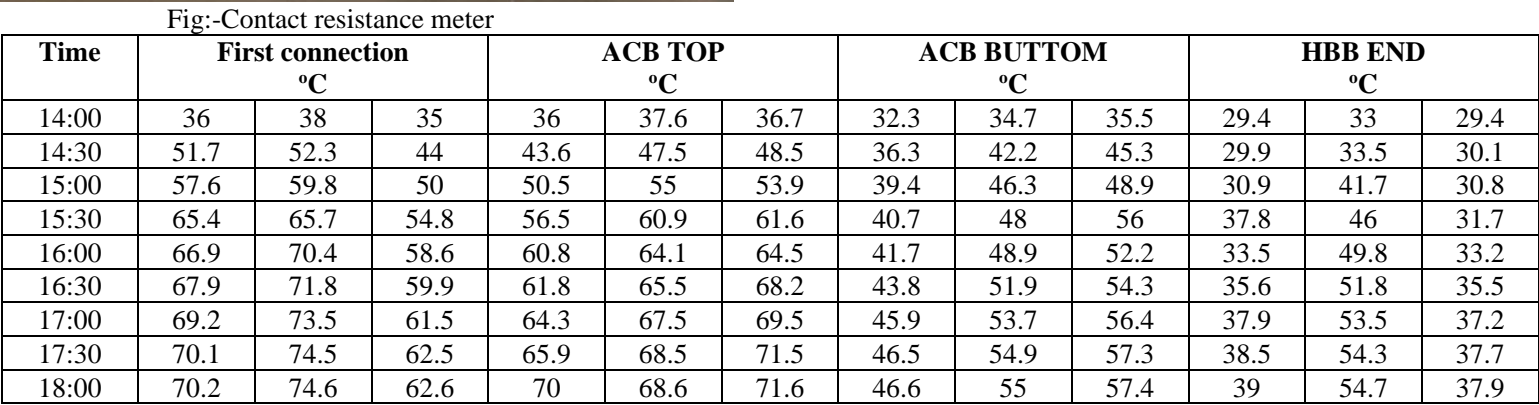

\section{- High voltage test}

This test also requires a HV testing kit the supply of $1.5 \mathrm{kv}$ to $2.5 \mathrm{kv} \mathrm{AC} 50 \mathrm{~Hz}$ is given for 10 seconds between any terminal and mounting plate

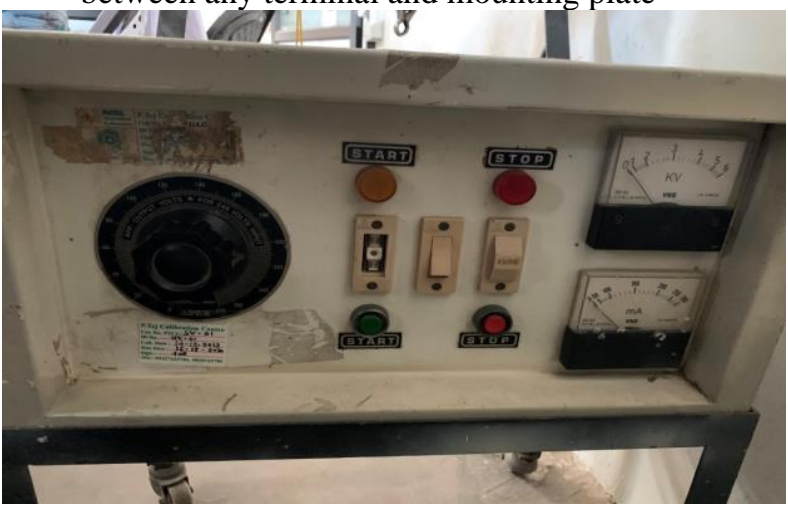

Fig:-High voltage tester

- Temperature rise test / Short circuit test

This test requires Auto transformer, low voltage high current transformer, bus bar assembly, bus bar short link. The mentioned apparatus are been connected to the panel. The main bus bar is been short from one end by the BB short link and another is been connected to the LVHI transformer and given supply for 4 hours. During this test it is essential to keep the breaker at the SC end to be connected and other breaker to be disconnected the temperature of bus bar should not exceed $90^{\circ} \mathrm{C}$ at any point of time as specified in the IEC standards. The below table shows the reading of temperature rise test:- 
The maximum temperature reach after 4 hours is $74.6^{\circ} \mathrm{C}$ and is are under $90^{\circ} \mathrm{C}$. The ambient temperature was $30^{\circ} \mathrm{C}$.

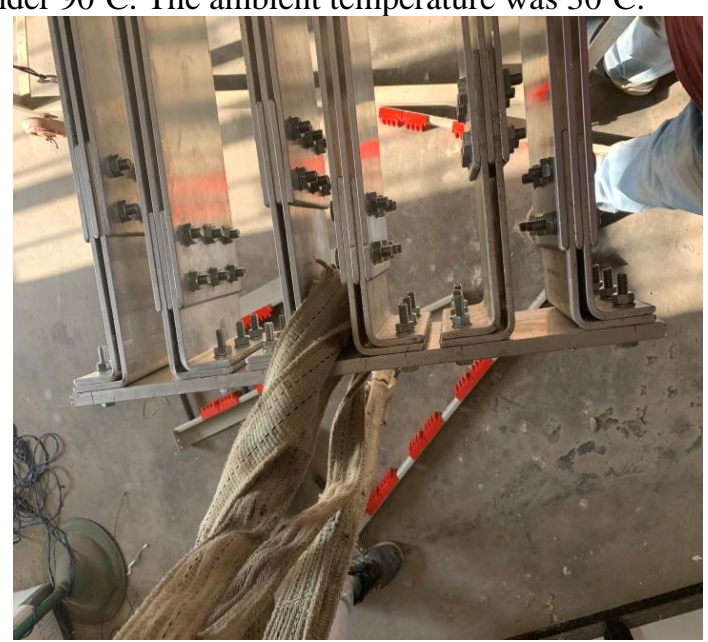

Fig:-(A)

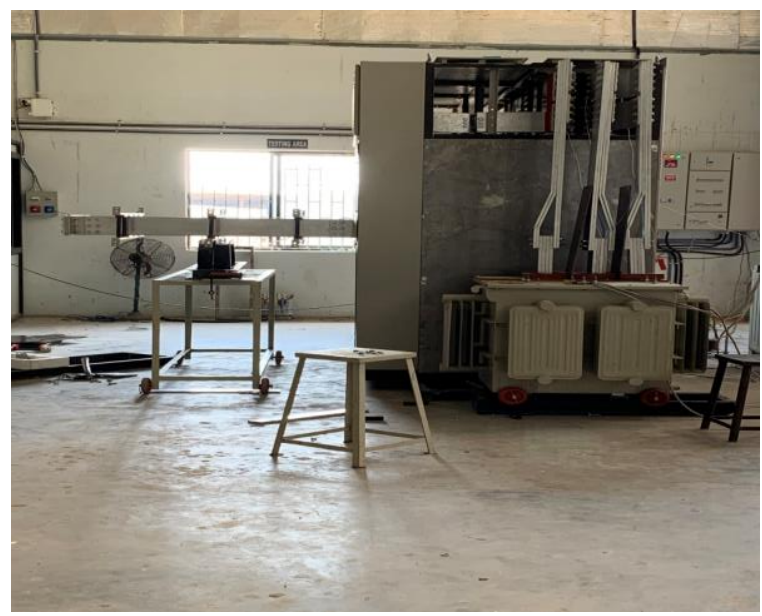

Fig;-(B)

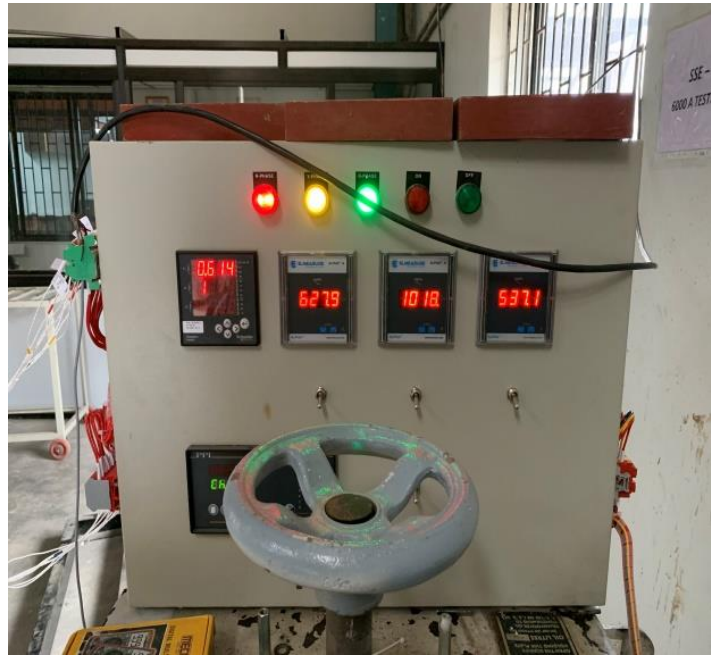

Fig:-(C)

Figure: - (A) Bus bar short circuit link

Figure: - (B) Arrangement of the equipment for the test

Figure: - (C) Display for the kit

\section{- CONCLUSION}

This paper has described the process of building Feeder panel from designing of the panel to the testing of panel. This paper also includes the designing parameters to be considered will designing of any rating of feeder panel. We can build any rateing of feeder panel with help of above given data.

\section{- REFERENCES}

[1] International Electrotechnical Commission 62271-1:2017. High voltage switch gear and control gear - part 1: common specifications for alternating current switchgear and control gear.

[2] International Electrotechnical Commission 62271-102:2018. High voltage switch gear and control gear - part 100: Alternating current disconnectors and earthing switches.

[3] International Electrotechnical Commission 62271-103:2011. High voltage switch gear and control gear - part 103 switches for rated voltages above $1 \mathrm{Kv}$ upto and including $52 \mathrm{Kv}$.

[4] Shiv Shakti Engineers - Technical support for designing, installation and testing of all parameters

[5] Switch gear manual, L\&T switch gears, U-POWER ACB- UWMTX3.5 